\title{
Phytotoxicity of alkaloids, coumarins and flavonoids isolated from 11 species belonging to the Rutaceae and Meliaceae families
}

\author{
Liliane Nebo $^{\text {a }}$, Rosa M. Varela ${ }^{\mathrm{b}}$, José M.G. Molinillo ${ }^{\mathrm{b}}$, Olívia M. Sampaio ${ }^{\mathrm{a}}$, \\ Vanessa G.P. Severino a, Cristiane M. Cazal ${ }^{a}$, Maria Fátima das Graças Fernandes a, \\ João B. Fernandes ${ }^{a}$, Francisco A. Macías ${ }^{\text {b,* }}$ \\ a Laboratory of Natural Products, Department of Organic Chemistry, Federal University of São Carlos, 13560-970 São Carlos (SP), Brazil \\ ${ }^{\mathrm{b}}$ Allelopathy Group, Department of Organic Chemistry, Institute of biomolecules (INBIO), School of Sciences University of Cádiz, 11510 Puerto Real (Cádiz), \\ Spain
}

\section{A R T I C L E I N F O}

\section{Article history:}

Received 7 February 2014

Received in revised form 14 February 2014

Accepted 21 February 2014

Available online 11 March 2014

\section{Keywords:}

Allelopathy

Phytotoxicity

Meliaceae

Rutaceae

Alkaloids

Coumarins

Flavonoids

\begin{abstract}
A B S T R A C T
Meliaceae and Rutaceae families are known for the high diversity of their secondary metabolites, which include many groups that represent a rich source of structural diversity, and are good candidates as sources of allelochemicals that could be useful in agriculture. In the work described here the bioactivity profiles were evaluated for 3 alkaloids (1-3), 12 coumarins (4-15), 2 phenylpropanoic acid derivatives (16 and 17) and 14 flavonoids (18-31) from 11 species belonging to the Meliaceae and Rutaceae families. All compounds were tested in the wheat coleoptile bioassay and those that showed the highest activities were tested on the STS (Standard Target Species) Lepidium sativum (cress), Lactuca sativa (lettuce), Lycopersicon esculentum (tomato), and Allium cepa (onion).

Most of the isolated compounds showed phytotoxic activity and graveoline (3), psoralen (8), and flavone (18) were the most active, with bioactivity levels similar to that of the commercial herbicide Logran ${ }^{\circledR}$. The results indicate that these compounds could be involved as semiochemicals in the allelopathic interactions of these plant species.
\end{abstract}

() 2014 Phytochemical Society of Europe. Published by Elsevier B.V. All rights reserved.

\section{Introduction}

Meliaceae and Rutaceae families are known for their high diversity of secondary metabolites, including many groups that represent a rich source of structural diversity. Alkaloids, coumarins, flavonoids, terpenes and limonoids are the largest groups of secondary plant metabolites and they show remarkable biological activities and have potential medicinal value (Tan and Luo, 2011; Champagne et al., 1992; Da Silva et al., 1984; Da Silva and Gottlieb, 1987).

The biological activity of the alkaloids has been actively explored and has been found to span a variety of properties (Michael, 2007, 2005). These include anticancer (Duarte et al., 2010; Zhai et al., 2012), antiparasitic (Silva et al., 2012; Mbeunkui et al., 2012; Mishra et al., 2009; Santos et al., 2009), antiinflammatory (Souto et al., 2011), antimicrobial (Joosten and Veen,

\footnotetext{
* Corresponding author. Tel.: +34 95601 2770; fax: +34 956016193 E-mail address: famacias@uca.es (F.A. Macías).
}

2011), and insecticidal (Bermúdez-Torres et al., 2009; Li et al., 2009) properties amongst others.

Coumarins are a large group of compounds that are widely distributed in many plant species and they have a wide spectrum of biological activities, including insecticidal (Pavela and Vrchotová, 2013), anticancer (Harada et al., 2010), Alzheimer's disease (Anand et al., 2012) and antimicrobial (Al-Amiery et al., 2012; Guan et al., 2011; Souza et al., 2005; Godoy et al., 2005; Sardari et al., 1999).

Flavonoids are also an important group of compounds and are widely found in the plant kingdom. They have a diverse range of significant bioactivities, including antioxidant (Wolfe and Liu, 2008), allelopathic (Treutter, 2006), gastroprotective (Mota et al., 2009), anticancer (Pick et al., 2011; Benavente-García and Castillo, 2008; Marchand, 2002), anti-inflammatory (García-Lafuente et al., 2009; Kim et al., 2004), and antimicrobial (Cushnie and Lamb, 2011; Salas et al., 2011) along with other effects.

The increased interest in crop protection, along with the extensive use of agrochemicals and the problems associated with their use, has led to the search for new biologically active natural products (Dayan et al., 2009). The discovery of new allelochemicals is an attractive alternative to current conventional herbicides used 


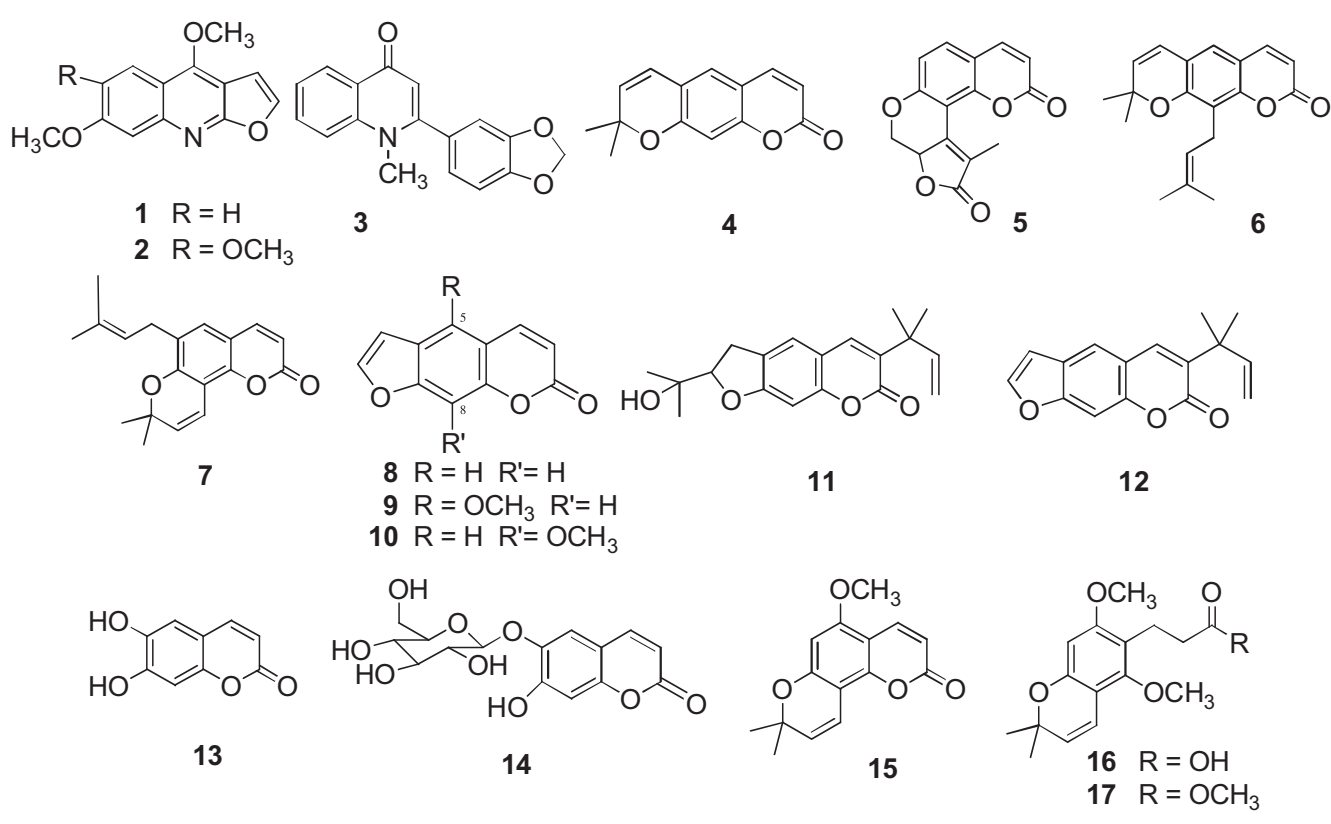

Fig. 1. Structures of the alkaloids (1-3) and coumarins (4-17) isolated from Meliaceae and Rutaceae families.

for weed control. Commercial herbicides have caused changes in populations of invasive species and environmental pollution and they have also enhanced the resistance phenomenon (Macías et al., 2007). In this context, Meliaceae and Rutaceae are good candidates to provide a source of allelochemicals for future use in agriculture.

The aim of the work described here was to evaluate the bioactivity profiles of three alkaloids (1-3), twelve coumarins (415), two phenylpropanoic acid derivatives (16 and 17) (Fig. 1) and fourteen flavonoids (18-31) (Fig. 2) from eleven species belonging to the Meliaceae and Rutaceae families.

\section{Results and discussion}

\subsection{Isolation of compounds}

The extraction, isolation and identification (NMR, MS, IR, UV data) of the following compounds has been described previously: $\mathbf{2}$ and $\mathbf{9}$ from roots and aerial parts of Ruta graveolens (Paulini et al., 1989; Masuda et al., 1998); 4 from roots of Citrus sinensis grafted on Citrus limonia (Cazal et al., 2009); 5 from stems and leaves of Raunia resinosa (Velozo et al., 1997); 7 from the fruit of Swinglea glutinosa (Santos, 2005); 15, 16 and 17 from stem and taproots of Hortia oreadica (Braga et al., 2012); 18, 23 and $\mathbf{2 4}$ from the fruit, branches and leaves of $C$. fruticosa Bl. (Leite et al., 2009); 21 from the fruit of Neoraputia magnifica (Tomazela et al., 2000; Passador et al., 1997); 22 from leaves of Neoraputia alba (Arruda et al., 1993); $\mathbf{2 5}$ and $\mathbf{2 9}$ from stems and leaves of Neoraputia paraensis (Moraes et al., 2003); 26 and $\mathbf{2 7}$ from peel; and $\mathbf{3 1}$ from the fruit of Murraya paniculata (Ferracin et al., 1998). Metabolites 13, 14, 19, $\mathbf{2 0 , 2 8}$ and $\mathbf{3 0}$ were obtained from commercial sources in order to carry out bioassays.

Compounds 1, 3, 8, 11 and 12 were isolated from the roots and aerial parts of $R$. graveolens, and $\mathbf{1 0}$ and $\mathbf{1 5}$ were obtained from taproots of $H$. oreadica as described in Section 3.

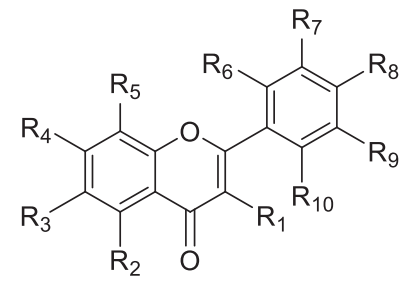

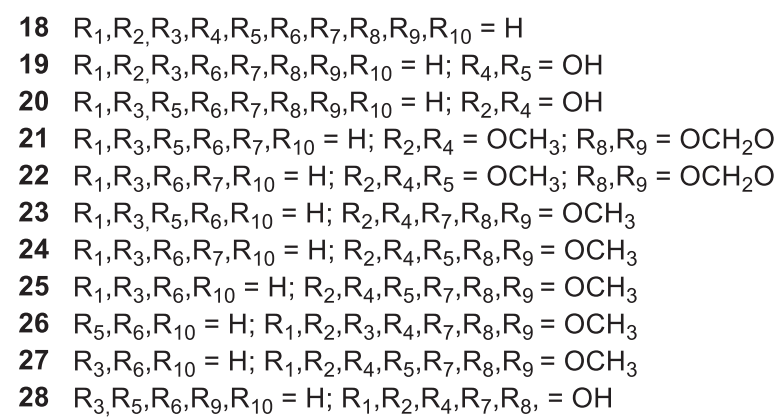<smiles>COc1cc(OC)c2c(c1)O[C@@H](c1cc(OC)c(OC)c(OC)c1)CC2=O</smiles>

31

Fig. 2. Structures of the flavonoids (18-31) isolated from Meliaceae and Rutaceae families. 


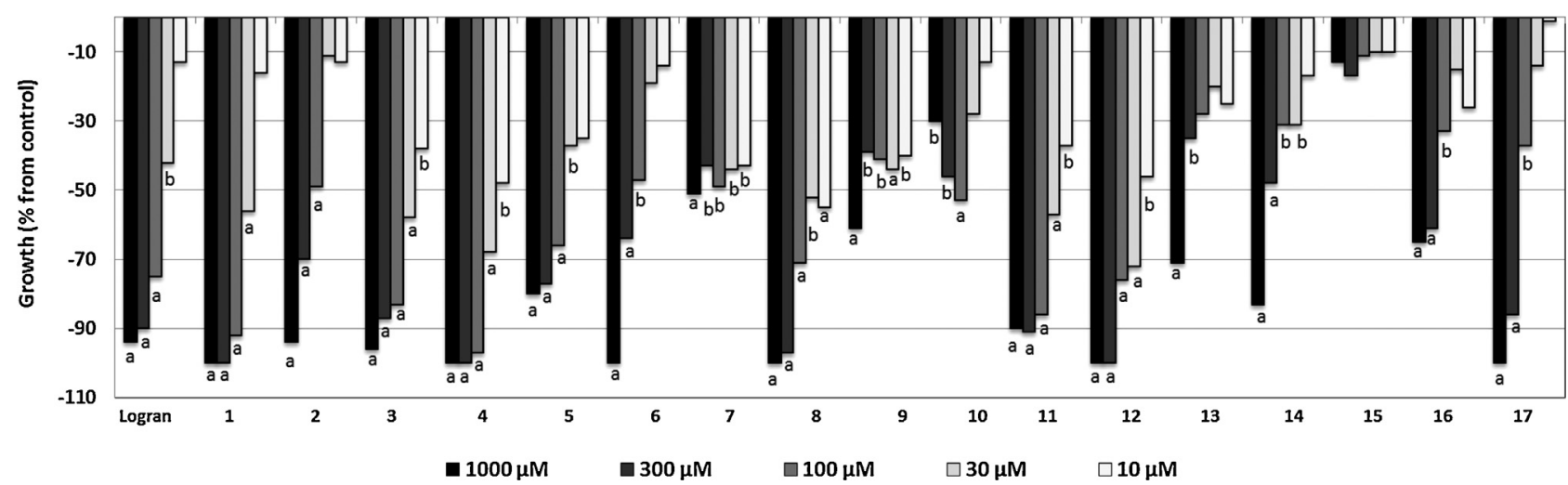

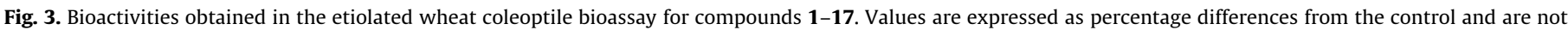
significantly different with $P>0.05$ for the Mann-Whitney test. ${ }^{\mathrm{a}}$ Values significantly different with $P<0.01$. ${ }^{\mathrm{b}}$ Values significantly different with $0.01<P<0.05$.

\subsection{Coleoptile bioassay results}

The etiolated wheat coleoptiles bioassay was used as an initial approach to evaluate the phytotoxicity of these compounds since it is a rapid test $(24 \mathrm{~h})$ that is sensitive to a wide range of bioactive substances (Cutler et al., 2000), including plant growth regulators, herbicides (Cutler, 1984), antimicrobials, mycotoxins and assorted pharmaceuticals (Jacyno and Cutler, 1993). The results are shown in Figs. 3 and 4, where negative values signify inhibition, positive values denote activation and zero represents control.

All alkaloids assayed were active. Evolitrine (1) and graveoline (3) presented the most consistent profiles, with levels of activity higher than $-85 \%$ at the first three concentrations tested ( $1 \mathrm{mM}$, $300 \mu \mathrm{M}$ and $100 \mu \mathrm{M}$ ) (Fig. 3). Kokusagine (2) differs from 1 in the presence of an additional methoxyl group at C- 6 but it only showed relevant activity levels at $1 \mathrm{mM}$ and $300 \mu \mathrm{M}(-94 \%$ and $-70 \%$ ).

Regarding coumarins, xanthyletin (4) was the most active of the pyranocoumarins $(\mathbf{4 - 7}, \mathbf{1 5})$. This compound completely inhibited coleoptile elongation at $1 \mathrm{mM}, 300 \mu \mathrm{M}$ and $100 \mu \mathrm{M}$ and the bioactivity was retained upon dilution $(-68 \%, 30 \mu \mathrm{M} ; 10 \mu \mathrm{M})$. Of the furanocoumarins, psoralen (8), chalepin (11) and chalepensin (12) showed good levels of activity. The most active compound was 12, which completely inhibited the coleoptile elongation at $1 \mathrm{mM}$ and $300 \mu \mathrm{M}$ with the bioactivity maintained upon dilution $(-76 \%$, $100 \mu \mathrm{M} ;-72 \%, 30 \mu \mathrm{M}$ and $-46 \%, 10 \mu \mathrm{M})$. These results allow some structural correlations to be made. For example, linear pyranocoumarins and furanocoumarins are preferred to angular compounds $(4,8,11$ and 12 vs. 5, 7 and 15). Furthermore, the absence of alkyl groups at C-8 (4 vs.6) and methoxyl groups ( 8 vs. 9 ,
10 and 15) leads to better results. However, the presence of prenyl groups bonded to $\mathrm{C}-3$ does not lead to a decrease in the activity ( 8 vs. 11 and 12). Simple coumarins (13 and 14) and phenylpropanoic acid derivatives ( $\mathbf{1 6}$ and $\mathbf{1 7}$ ) showed inhibition effects of between $-70 \%$ and $-100 \%$ at the highest concentration, although the activities of these compounds decrease rapidly with dilution.

Regarding flavonoids, the most active compounds were flavone (18) and 3',4'-methylenedioxy-5,7-dimethoxyflavone (21), which gave values of around $-98 \%$ and $-76 \%$ at $1 \mathrm{mM}$, respectively. $3^{\prime}, 4^{\prime}, 5,5^{\prime}, 7$-Pentamethoxyflavone (23) did not show the highest levels of inhibition at $1 \mathrm{mM}$ and $300 \mu \mathrm{M}(-47 \%$ and $-57 \%$, respectively), but the bioactivity was maintained upon dilution $(-51 \%, 100 \mu \mathrm{M} ;-44 \%, 30 \mu \mathrm{M}$ and $-44 \%, 10 \mu \mathrm{M})$ (Fig. 4). There is no clear substitution pattern that would indicate whether compounds are active or not. The introduction of hydroxyl and methoxyl groups seems to influence the bioactivity and small structural differences can change the activity markedly, as can be observed for 21 and 22 (Macías et al., 1997).

\subsection{Phytotoxicity bioassay}

The most active compounds, alkaloids $\mathbf{1}$ and $\mathbf{3}$, pyranocoumarins 4 and 8, furanocoumarins 11 and 12 and the flavones 18, 21 and 23 were selected for phytotoxicity evaluation on the standard target species (STS) Lepidium sativum (cress), Lactuca sativa (lettuce), Lycopersicon esculentum (tomato), and Allium cepa (onion). The commercial herbicide Logran ${ }^{\circledR}$ was used as internal standard (Macías et al., 2000). The results of the bioassay are presented in Figs. 5 and 6, where data are presented as percentage differences from the control. The concentrations tested were

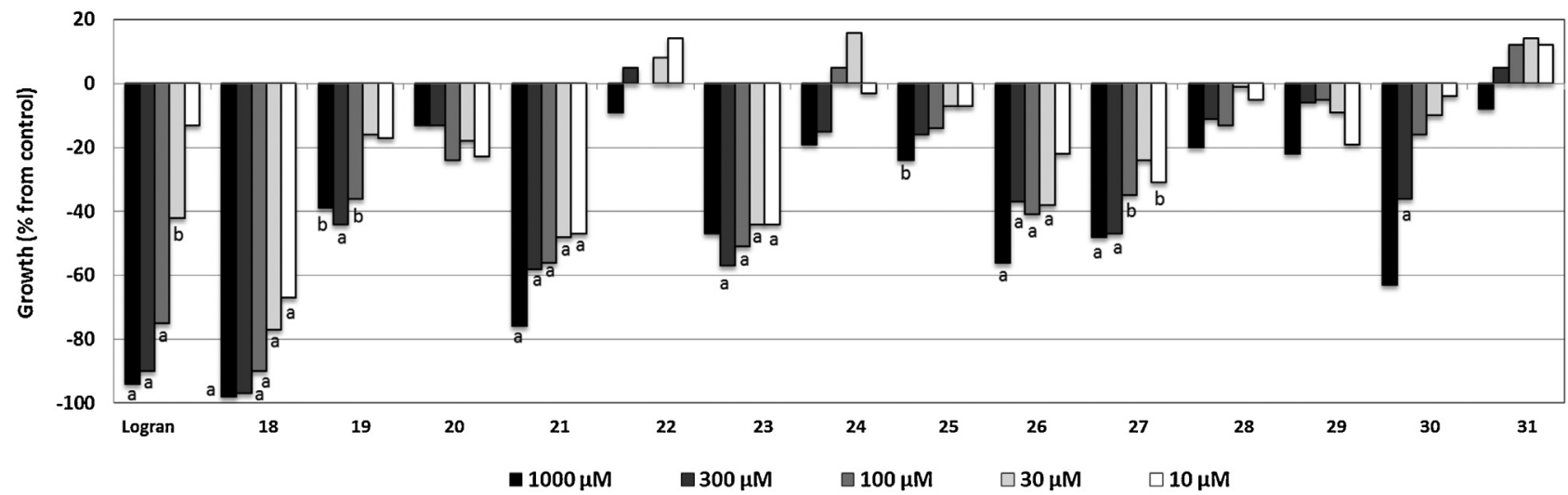

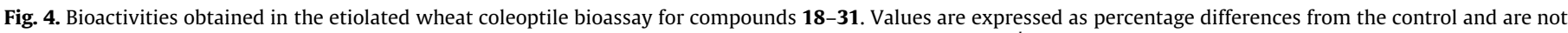
significantly different with $P>0.05$ for the Mann-Whitney test. ${ }^{\text {a }}$ Values significantly different with $P<0.01$. ${ }^{\text {b}}$ Values significantly different with $0.01<P<0.05$. 

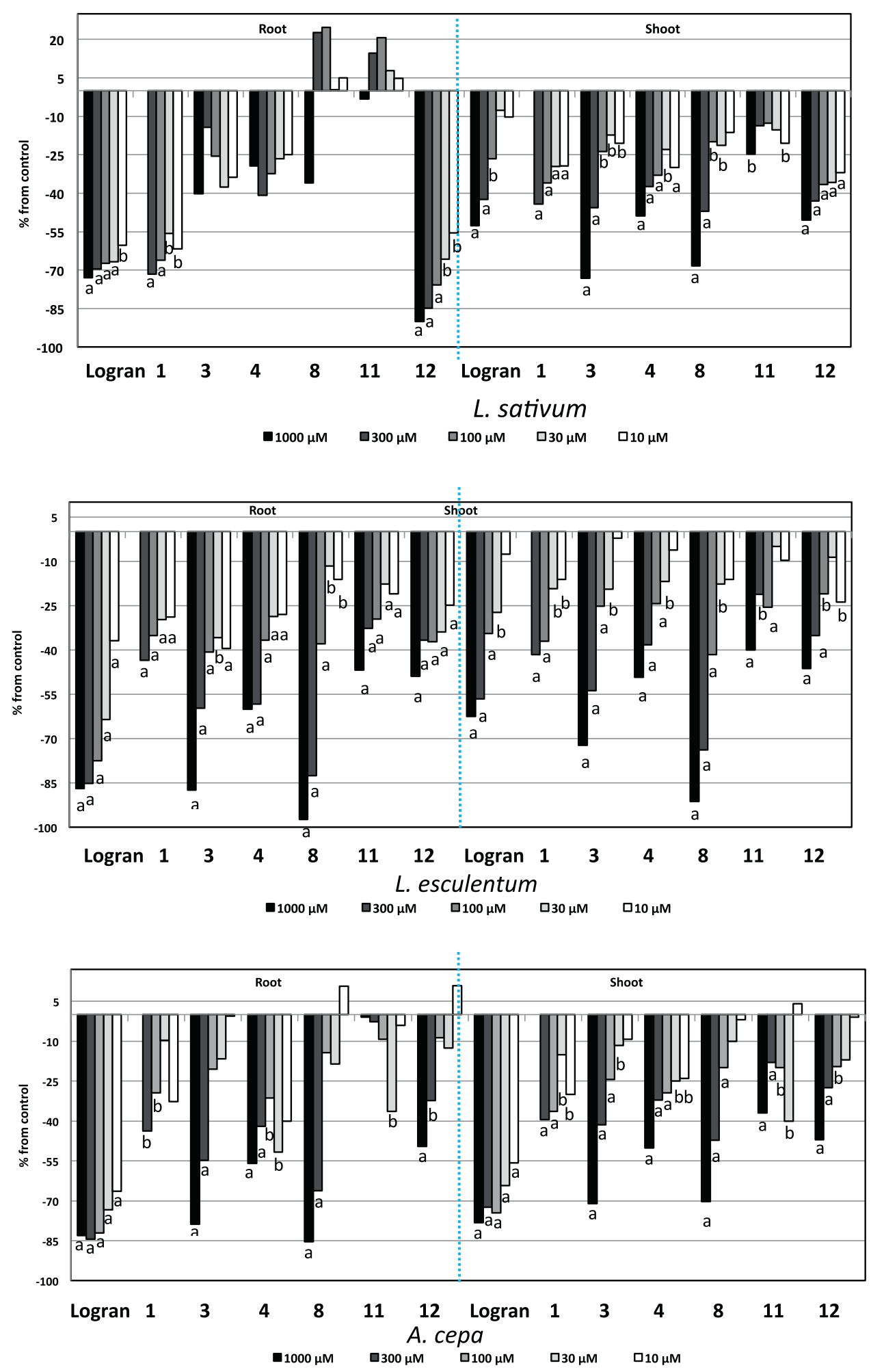

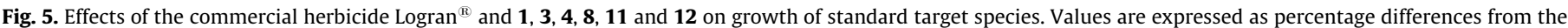

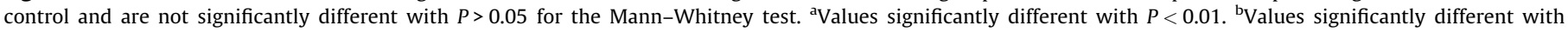
$0.01<P<0.05$.

identical to those in the coleoptile bioassay, with the exception of 1, for which the highest concentration was $300 \mu \mathrm{M}$.

The least affected parameter was germination, apart from compounds $\mathbf{3}$ and $\mathbf{8}$, which inhibited germination of $L$. sativum, $L$. esculentum and $A$. cepa.

Regarding the dicotyledonous species, $L$. sativum, the compounds evolitrine (1) and chalepensin (12) were the most active and they inhibited root growth at all concentrations with similar levels to the herbicide Logran $^{\circledR}$ (positive control). Graveoline (3) and psoralen (8) showed the best results on shoot growth, with values of $-75 \%$ and $-69 \%$, respectively, at the highest concentration $\left(10^{-3} \mathrm{M}\right)$ (Fig. 5). Compounds $\mathbf{3}$ and 8 also affected the germination ( $-62 \%$ and $-83 \%$, respectively, at $1 \mathrm{mM})$. 


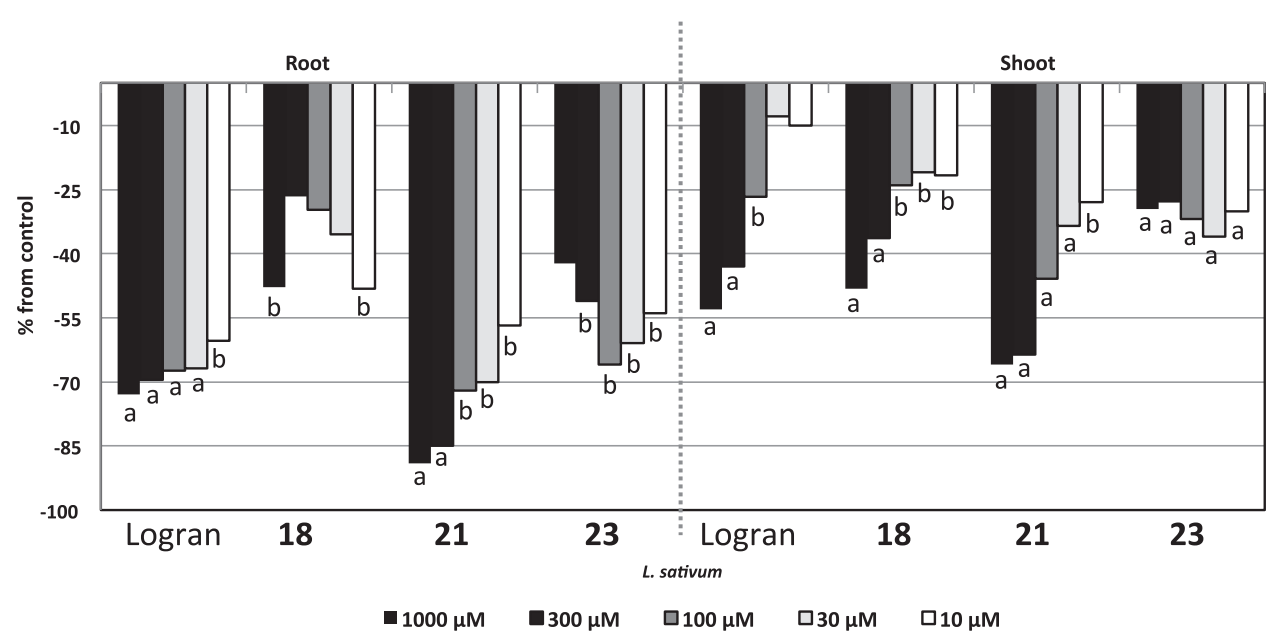

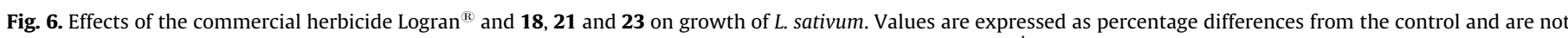
significantly different with $P>0.05$ for the Mann-Whitney test. ${ }^{\mathrm{a} V a l u e s}$ significantly different with $P<0.01$. ${ }^{\mathrm{b}}$ Values significantly different with $0.01<P<0.05$.

Compound 21 was the most active flavone on germination and growth of L. sativum and it showed similar levels of phytotoxicity to the herbicide Logran ${ }^{\circledR}$ (Fig. 6). The effect on other species was not significant. The behavior of $\mathbf{1 8}$ and $\mathbf{2 3}$ was not significant on STS species.

Regarding L. sativa, the most active compounds were $\mathbf{8}$ and $\mathbf{1 2}$ and these affected the root growth at the highest concentration ( $-65 \%$ and $-56 \%$, respectively, at $1 \mathrm{mM}$ ). The growth of $L$. esculentum and A. cepa was also affected by the tested compounds - especially in the cases of $\mathbf{3}$ and $\mathbf{8}$, which inhibited both parameters in both species.

Hale et al., 2004 demonstrated that 3 affected the growth of the aquatic plant Lemma paucicostata at $100 \mu \mathrm{M}$ and caused tissue degradation at $250 \mu \mathrm{M}$ and above. On the other hand, compounds $\mathbf{4 , 9}$, and 10 have been previously tested on L. sativa and it was proposed that these compounds are responsible for the allelopathic activity of Pilocarpus goudotianus (Macías et al., 1993).

Although xanthyletin (5) and chalepin (11) have shown only moderate phytotoxicity levels on STS species, they inhibited the root growth of Amaranthus hypochondriacus (Anaya et al., 2005). Sampaio et al., 2012 evaluated the photosynthesis inhibition potential of furanocoumarins and highlighted chalepin (11) as a photosynthesis inhibitor.

We propose Meliaceae and Rutaceae to be good candidates to provide sources of allelochemicals that may be useful in agriculture. The isolated compounds showed phytotoxic activity and graveoline (3), psoralen (8) and flavone (18) were the most active, with bioactivity levels similar or even better than the commercial herbicide Logran ${ }^{\mathbb{R}}$. The bioactivities of these compounds indicate that these products could also be involved as semiochemicals in the allelopathic interactions of these plant species.

\section{Experimental}

\subsection{Plant material}

R. graveolens was collected in Akai Ranch, located in Atibaia, São Paulo State, Brazil; $H$. oreadica Groppo was collected in Forest Reserve Adolpho Ducke, Itacoatiara, Amazonas State, Brazil; C. sinensis grafted on C. limonia was collected in Estação Experimental de Citricultura do Instituto Agronômico de Campinas, Cordeirópolis, SP, Brazil; R. resinosa (Nees et. Mart.) was collected in Cachoeiro do Itapemirim, Espírito Santo State, Brazil; M. paniculata was collected in São Carlos, SP, Brazil; Cipadessa fruticosa Bl and $N$. magnifica were collected in Viçosa, MG, Brazil; $N$. alba and $R$. resinosa (Nees et. Mart.) were collected in Cachoeiro do Itapemirim, Espírito Santo State, Brazil. The plants were identified by Dr. José R. Pirani from the Department of Botany, University of São Paulo and vouchers were deposited at the Herbarium at the same Department.

S. glutinosa (Bl.) Merr. was collected in Campinas, SP, Brazil, and identified by Prof. Dr. Maria Inês Salgado. A voucher specimen is deposited at the Herbarium of the Botany Department, Federal University of São Carlos (UFSCar) as number 7110.

\subsection{Extraction and isolation}

\subsubsection{Isolation of $\mathbf{1}, \mathbf{3}, \boldsymbol{8}, \mathbf{1 1}$ and $\mathbf{1 2}$ from Ruta graveolens}

Dried roots $(1.6 \mathrm{~kg})$ and aerial parts $(3.4 \mathrm{~kg})$ were extracted with cold ethanol using a homogenizer for 3 days. The ethanolic solution was concentrated under reduced pressure and the crude extract of aerial parts was chromatographed using silica gel (CC) to afford the following fractions: hexane (13.8 g), $\mathrm{CH}_{2} \mathrm{Cl}_{2}(25.0 \mathrm{~g})$ and $\mathrm{MeOH}$ (95.0 g). The liquid/liquid partition technique was used to fractionate the root extract into the following fractions: hexane (1.53 g), $\mathrm{CH}_{2} \mathrm{Cl}_{2}$ (1.55 g), EtOAc (1.87 g) and water (1.99 g). The $\mathrm{CH}_{2} \mathrm{Cl}_{2}$ fraction from the aerial parts was chromatographed on $\mathrm{SiO}_{2}$ $(70-230$ mesh; $5.3 \mathrm{~cm} \times 21.0 \mathrm{~cm})$ in vacuum and eluted with hexane (A), $\mathrm{CH}_{2} \mathrm{Cl}_{2}$ (B) and $\mathrm{MeOH}$ (C) to yield three fractions. The $\mathrm{CH}_{2} \mathrm{Cl}_{2}$ fraction (B) from the aerial parts was fractionated on $\mathrm{SiO}_{2}$, eluted with hexane, $\mathrm{CH}_{2} \mathrm{Cl}_{2}, \mathrm{Me}_{2} \mathrm{CO}$ and $\mathrm{MeOH}$ to afford 20 fractions from which $8(110.0 \mathrm{mg})$ and $12(230.0 \mathrm{mg})$ were isolated. These new fractions were further purified by HPLC [Phenyl-Hexyl $(0.7 \times 30 \mathrm{~cm})$ and particle size of $10 \mu \mathrm{m}$ ], with elution in the isocratic mode: $\mathrm{MeOH}: \mathrm{CH}_{2} \mathrm{Cl}_{2}, 1: 1$ (v/v), flow rate $=3.0 \mathrm{~mL} \mathrm{~min}^{-1}$. Detection (Shimadzu SCL-10A) was carried out at $\lambda=254$ and $365 \mathrm{~nm}$ and compound 11 (52.2 mg) was isolated. The $\mathrm{MeOH}$ fraction (C) from the aerial parts was purified on Sephadex $\mathrm{LH}-20$ in isocratic mode ( $\left.\mathrm{MeOH}: \mathrm{CH}_{2} \mathrm{Cl}_{2}, 1: 1(\mathrm{v} / \mathrm{v})\right)$ and compound 3 (35.2 mg) was isolated. The $\mathrm{CH}_{2} \mathrm{Cl}_{2}$ fraction from the roots was fractionated on $\mathrm{SiO}_{2}$, eluted with hexane, $\mathrm{CH}_{2} \mathrm{Cl}_{2}, \mathrm{Me}_{2} \mathrm{CO}$ and $\mathrm{MeOH}$. A total of 30 fractions were collected and 1 (13.2 mg) was isolated.

The structures of the compounds were established by comparison of their spectroscopic and physical data with those reported in the literature (Hongwei et al., 2010; Masuda et al., 1998; Ngadjui et al., 1998; Oliveira et al., 1996; Kumar et al., 1995). 


\subsubsection{Isolation of $\mathbf{1 0}$ and $\mathbf{1 5}$ from $\mathrm{H}$. oreadica}

The taproots $(3.3 \mathrm{~kg}$ ) of $\mathrm{H}$. oreadica were dried carefully by forced air at $40{ }^{\circ} \mathrm{C}$ and the sample was powdered. The sample was extracted to give the crude extracts as follows: hexane $(86.0 \mathrm{~g})$, $\mathrm{CH}_{2} \mathrm{Cl}_{2}(68.0 \mathrm{~g})$ and $\mathrm{MeOH}(244.0 \mathrm{~g})$. The $\mathrm{CH}_{2} \mathrm{Cl}_{2}$ extract was chromatographed on $\mathrm{SiO}_{2}$ under vacuum, eluted with hexane $(1.0 \mathrm{~L}), \mathrm{CH}_{2} \mathrm{Cl}_{2}(1.0 \mathrm{~L})$, EtOAc $(3.0 \mathrm{~L})$ and $\mathrm{MeOH}(1.0 \mathrm{~L})$ to yield 4 fractions. The EtOAc fraction was chromatographed on $\mathrm{SiO}_{2}(230-$ 400 mesh; $4.0 \mathrm{~cm} \times 24.0 \mathrm{~cm}$ ), eluted with a hexane $/ \mathrm{MeOH}$ gradient to give 20 new fractions. Fraction 8 was purified on $\mathrm{SiO}_{2}(230-400$ mesh; $5.0 \mathrm{~cm} \times 30.0 \mathrm{~cm})$ eluted with hexane/EtOAc with increasing polarity to afford compound $\mathbf{5}(128.0 \mathrm{mg})$. Fraction 13 was chromatographed on $\mathrm{SiO}_{2}$ (230-400 mesh; $4.0 \mathrm{~cm} \times 30.0 \mathrm{~cm})$ using the same methodology described above to yield compound $\mathbf{1 0}(4.0 \mathrm{mg})$.

Structures of compounds were established by comparison of their spectroscopic and physical data with those reported in the literature (Melliou et al., 2005; Masuda et al., 1998).

The purities of all compounds were evaluated by HPLC prior the bioassay and they all had a purity higher than $98 \%$.

\subsection{Coleoptiles bioassay}

Wheat seeds (Triticum aestivum L. cv. Duro) were sown in $15 \mathrm{~cm}$ diameter Petri dishes moistened with water and grown in the dark at $22 \pm 1{ }^{\circ} \mathrm{C}$ for 3 days (Hancock et al., 1964). The roots and caryopses were removed from the shoots. The latter were placed in a Van der Weij guillotine, and the apical $2 \mathrm{~mm}$ were cut off and discarded. The next $4 \mathrm{~mm}$ of the coleoptiles were removed and used for the bioassays. All manipulations were performed under a green safelight (Nitsch and Nitsch, 1956). Compounds were predissolved in DMSO and diluted to the final bioassay concentration with a maximum of 0.1\% DMSO. Parallel controls were also run. The compounds to be assayed for biological activity were added to test tubes. Phosphatecitrate buffer ( $2 \mathrm{~mL}$ ) containing $2 \%$ sucrose (Nitsch and Nitsch, 1956) at $\mathrm{pH} 5.6$ was added to each test tube. Five coleoptiles were placed in each test tube (three tubes per dilution) and the tubes were rotated at $0.25 \mathrm{rpm}$ in a roller tube apparatus for $24 \mathrm{~h}$ at $22^{\circ} \mathrm{C}$ in the dark. The coleoptiles were measured by digitalization of their images. Data were statistically analyzed using Welch's test (Martín Andrés and Luna del Castillo, 1990). Data are presented as percentage differences from control. Thus, zero represents the control, positive values represent stimulation of the studied parameter, and negative values represent inhibition.

\subsection{Phytotoxicity bioassay}

The selection of target plants was based on an optimization process developed by us in our search for a standard phytotoxicity bioassay (Macías et al., 2000). Several Standard Target Species (STS) were proposed, including monocots T. aestivum L. (wheat) and $A$. cepa L. (onion) and dicots $L$. esculentum Will. (tomato), $L$. sativum L. (cress) and L. sativa L. (lettuce), which were assayed for this study. Bioassays were conducted using Petri dishes $(50 \mathrm{~mm}$ diameter), with one sheet of Whatman No. 1 filter paper as support. Germination and growth were conducted in aqueous solutions at controlled $\mathrm{pH}$ using $10^{-2} \mathrm{M}$ 2-[N-morpholino]ethanesulfonic acid (MES) and $1 \mathrm{M} \mathrm{NaOH}(\mathrm{pH} \mathrm{6.0)}$.

Compounds to be assayed were dissolved in DMSO $(0.1,0.02$, 0.01 and $0.002 \mathrm{M}$ ) and these solutions were diluted with buffer (5 $\mu$ l DMSO solution/ml buffer) so that test concentrations for each compound $\left(3 \times 10^{-4}, 10^{-4}, 3 \times 10^{-5}\right.$ and $\left.10^{-5} \mathrm{M}\right)$ were achieved. This procedure facilitated the solubility of the assayed compounds. The number of seeds in each Petri dish depended on the seed size. 20 seeds were used for tomato, lettuce, cress and onion. Treatment, control or internal reference solution $(1 \mathrm{ml})$ was added to each
Petri dish. Four replicates were used for tomato, cress, onion and lettuce ( 80 seeds). After adding seeds and aqueous solutions, Petri dishes were sealed with Parafilm to ensure closed-system models. Seeds were further incubated at $25^{\circ} \mathrm{C}$ in a Memmert ICE 700 controlled environment growth chamber in the dark. Bioassays took 4 days for cress, 5 days for lettuce and tomato and 7 days for onion.

After growth, plants were frozen at $-10{ }^{\circ} \mathrm{C}$ for $24 \mathrm{~h}$ to avoid subsequent growth during the measurement process. The commercial herbicide $\operatorname{Logran}^{\circledR}$, a combination of 2-tert-butylamino-4ethylamino-6-methylthio-1,3,5-triazine (terbutryn, 59.4\%) and 1[2-(2-chloroethoxy)phenylsulfonyl]-3-(4-methoxy-6-methyl-

$1,3,5$-triazin-2-yl)urea (triasulfuron, $0.6 \%$ ), was used as an internal reference according to a comparison study reported previously (Macías et al., 2000).

The herbicide was used at the same concentrations ( $1 \mathrm{mM}, 300$, $100,30,10 \mu \mathrm{M}$ ) and under the same conditions as those reported. Control samples (buffered aqueous solutions with DMSO and without any test compound) were used for all of the plant species assayed.

Evaluated parameters (germination rate, root length and shoot length) were recorded using a Fitomed ${ }^{\odot}$ system (Castellano et al., 2001), which allowed automatic data acquisition and statistical analysis using its associated software. Data were analyzed statistically using Welch's test, with significance fixed at 0.01 and 0.05 . Results are presented as percentage differences from the control. Zero represents control, positive values represent stimulation, and negative values represent inhibition.

\section{Acknowledgements}

This research was supported by the Consejería de Economía, Innovación, Ciencia y Empleo, Junta de Andalucia, Spain (Project No. P10-AGR-5822). One of the authors (L. Nebo) thanks CAPES (Coordenação de Aperfeiçoamento de Pessoal de Nível Superior, Brazil) and FAPESP (Fundação de Amparo à Pesquisa do Estado de São Paulo, Brazil) for scholarships.

\section{References}

Al-Amiery, A.A., Kadhum, A.A.H., Mohamad, A.B., 2012. Antifungal activities of new coumarins. Molecules 17, 5713-5723.

Anaya, A.L., Macías-Rubalcava, M., Cruz-Ortega, R., García-Santana, C., SánchezMonterrubio, P.N., Hernández-Bautista, B.E., Mata, R., 2005. Allelochemicals from Stauranthus perforatus, a Rutaceous tree of the Yucatan Peninsula, Mexico. Phytochemistry 66, 487-494.

Anand, P., Singh, B., Singh, N., 2012. A review on coumarins as acetylcholinesterase inhibitors for Alzheimer's disease. Bioorg. Med. Chem. 20, 1175-1180.

Arruda, A.C., Vieira, P.C., Fernandes, J.B., Silva, M.F.G.F., 1993. Further pyrano flavones from Neoraputia alba. J. Braz. Chem. Soc. 4, 80-83.

Benavente-García, O., Castillo, J., 2008. Update on uses and properties of Citrus Flavonoids: new findings in anticancer, cardiovascular, and anti-inflammatory activity. J. Agric. Food Chem. 56, 6185-6205.

Bermúdez-Torres, K., Herrera, J.M., Brito, R.F., Wink, M., Legal, L., 2009. Activity of quinolizidine alkaloids from three Mexican Lupinus against the lepidopteran crop pest Spodoptera frugiperda. BioControl 54, 459-466.

Braga, P.A.C., Severino, V.G.P., Freitas, S.D.L., Silva, M.F.G.F., Fernandes, J.B., Vieira, P.C., Pirani, J.R., Groppo, M., 2012. Dihydrocinnamic acid derivatives from Hortia species and their chemotaxonomic value in the Rutaceae. Biochem. Syst. Ecol. 43, 142-151.

Castellano, D., Macías, F. A., Castellano, M., Cambronero, R., 2001. Spanish Patent N ${ }^{\circ}$ P9901565.

Cazal, C.M., Domingues, V.C., Batalhão, J.R, Bueno, O.C., Rodrigues-Filho, E., Silva, M.F.G.F., Vieira, P.C., Fernandes, J.B., 2009. Isolation of xanthyletin, an inhibitor of ants' symbiotic fungus, by high-speed couter-current chromatography. J. Chromatogr. A 1216, 4307-4312.

Champagne, D.E., Koul, O., Isman, M.B., Scudder, G.G.E., Towers, G.H.N., 1992. Biological activity of limonoids from the Rutales. Phytochemistry 31, 377-394. Cushnie, T.P.T., Lamb, A.J., 2011. Recent advances in understanding the antibacterial properties of flavonoids. Int. J. Antimicrob. Ag. 38, 99-107.

Cutler, H.G., 1984. Fresh look at the wheat coleoptile bioassay. In: Proceedings of the $11^{\text {th }}$ Annual Meeting of the Plant Growth Regulator Society of America. PGRSA, Boston, MS, USA, pp. 1-9. 
Cutler, S.J., Hoagland, R.E., Cutler, H.G., 2000. Evaluation of selected pharmaceuticals as potential herbicides: Bridging the gap between agrochemicals and pharmaceuticals. In: Narwal, s.s., Hoagland, R.E., Dilday, R.H., Reigosa Roger, M.J. (Eds.), Allelopathy in Ecological Agriculture and Forestry. Springer, Dordrecht, The Netherlands, pp. 129-137.

Da Silva, M.F.G.F., Gottlieb, O.R., Dreyer, D.L., 1984. Evolution of Limonoids in the Meliaceae. Biochem. Syst. Ecol. 12, 299-310.

Da Silva, M.F.G.F., Gottlieb, O.R., 1987. Evolution of quassinoids and limonoids in the Rutales. Biochem. Syst. Ecol. 15, 85-103.

Dayan, F.E., Cantrell, C.L., Duke, S.O., 2009. Natural products in crop protection. Bioorg. Med. Chem. 17, 4022-4034.

Duarte, R.A., Mello, E.R., Araki, C., Bolzani, V.S., Silva, D.H.S., Regasini, L.O., Silva, T.G.A., Morais, M.C.C., Ximenes, V.F., Soares, C.P., 2010. Alkaloids extracted from Pterogyne nitens induce apoptosis in malignant breast cell line. Tumor Biol. 31, 513-522.

Ferracin, R.J., Silva, M.F.G.F., Fernandes, J.B., Vieira, P.C., 1998. Flavonoids from the fruits of Murraya paniculata. Phytochemistry 47, 393-396.

García-Lafuente, A., Guillamón, E., Villares, A., Rostagno, M.A., Martínez, J.A., 2009. Flavonoids as anti-inflammatory agents: implications in cancer and cardiovascular disease. Inflamm. Res. 58, 537-552.

Godoy, M.F.P., Victor, S.R., Bellini, A.M., Guerreiro, G., Rocha, W.C., Bueno, O.C., Hebling, M.J.A., Bacci Jr., M., Silva, M.F.G.F., Vieira, P.C., Fernandes, J.B., Pagnocca, F.C., 2005. Inhibition of the symbiotic fungus of leaf-cutting ants by coumarins. J. Brazil Chem. Soc. 16, 669-672.

Guan, A., Liu, C., Li, M., Zhang, H., Li, A., Li, Z., 2011. Design, synthesis and structureactivity relationship of novel coumarin derivatives. Pest Manag. Sci. 67, 647-655.

Hale, A.L., Meepagala, K.M., Oliva, A., Aliotta, G., Duke, S.O., 2004. Phytotoxins from the leaves of Ruta graveolens. J. Agric. Food Chem. 52, 3345-3349.

Hancock, C.R., Barlow, H.W., Lacey, H.J., 1964. The east malling coleoptile straight growth test method. J. Exp. Bot. 15, 166-176.

Harada, K., Kubo, H., Tomigahara, Y., Nishioka, K., Takahashi, J., Momose, M., Inoue, S., Kojima, A., 2010. Coumarins as novel 17- $\beta$-hydroxysteroid dehydrogenase type 3 inhibitors for potential treatment of prostate cancer. Bioorg. Med. Chem. Lett. 20, 272-275.

Hongwei, Y., Bogang, L., Xiaozhen, C., Changsong, L., Guolin, Z., 2010. Chemical study on Evodia vestita. Chin. J. Appl. Environ. Biol. 16, 72-75.

Jacyno, J.M., Cutler, H.G., 1993. Detection of herbicidal properties: scope, and limitations of the etiolated wheat coleoptiles bioassay. PGRSA Quarterly 21, 15-24.

Joosten, L., Veen, J.A., 2011. Defensive properties of pyrrolizidine alkaloids against microorganisms. Phytochem. Rev. 10, 127-136.

Kim, H.P., Son, K.H., Chang, H.W., Kang, S.S., 2004. Anti-inflammatory plant flavonoids and cellular action mechanisms. J. Pharmacol. Sci. 96, 229-245.

Kumar, V., Vallipuram, K., Adebajo, A.C., Reisch, J., 1995. 2,7-Dihydroxy-3-formyl-1(3'-methyl-2'-butenyl)carbazole from Clausena lansium. Phytochemistry 40, 1563-1565.

Leite, A.C., Ambrozin, A.R.P., Castilho, M.S., Vieira, P.C., Fernandes, J.B., Oliva, G., Silva, M.F.G.F., Thiemann, O.H., Lima, M.I.S., Pirani, J.R., 2009. Screening of Trypanosoma cruzi glycosomal glyceraldehyde-3-phosphate dehydrogenase enzyme inhibitors. Braz. J. Pharmacogn. 19, 1-6.

Li, Z., Gu, Y., Irwin, D., Sheridan, J., Clough, J., Chen, P., Peng, S., Yang, Y., Guo, Y., 2009. Further Daphniphyllum alkaloids with insecticidal activity from the bark of Daphniphyllum macropodum MiQ. Chem. Biodiv. 6, 1744-1750.

Macías, F.A., Galindo, J.C.G., Massanet, G.M., Rodriguez-Luis, F., Zubia, E., 1993. Allelochemicals from Pilocarpus goudotianus leaves. J. Chem. Ecol. 19, $1371-$ 1379.

Macías, F.A., Molinillo, J.M.G., Torres, A., Varela, R.M., Castellano, D., 1997. Bioactive flavonoids from Helianthus annuus cultivars. Phytochemistry 45, 683-687.

Macías, F.A., Castellano, D., Molinillo, J.M.G., 2000. Search for a standard phytotoxic bioassay for allelochemicals. Selection of standard target species. J. Agric. Food Chem. 48, 2512-2521.

Macías, F.A., Molinillo, J.M.G., Varela, R.M., Galindo, J.C.G., 2007. Allelopathy - a natural alternative for weed control. Pest Manag. Sci. 63, 327-348.

Marchand, L.L., 2002. Cancer preventive effects of flavonoids - a review. Biomed. Pharmacother. 56, 296-301.

Martín Andrés, A., Luna Del Castillo, J.D., 1990. Bioestadística para las Ciencias de la Salud, 3rd ed. Norma, Madrid.

Masuda, T., Takasugi, M., Aneta, M., 1998. Psoralen and other linear furanocoumarins as phytoalexins in Glehnia littoralis. Phytochemistry 47, 13-16.

Mbeunkui, F., Grace, M.H., Lategan, C., Smith, P.J., Raskin, I., Lila, M.A., 2012. In vitro antiplasmodial activity of indole alkaloids from the stem bark of Geissospermum vellosii. J. Ethnopharmacol. 139, 471-477.

Melliou, E., Magiatis, P., Mitaku, S., Skaltsounis, A., Chinou, E., Chinou, I., 2005. Natural and synthetic 2,2-dimethylpyranocoumarins with antibacterial activity. J. Nat. Prod. 68, 78-82

Michael, J.P., 2007. Quinoline, quinazoline and acridone alkaloids. Nat. Prod. Rep. 24, 223-246.
Michael, J.P., 2005. Quinoline, quinazoline and acridone alkaloids. Nat. Prod. Rep. 22, 627-646.

Mishra, B.B., Kale, R.R., Singh, R.K., Tiwan, V.K., 2009. Alkaloids: future prospective to combat leishmaniasis. Fitoterapia 80, 81-90.

Moraes, V.R.S., Tomazela, D.M., Ferracin, R.J., Garcia, C.F., Sannomiya, M., Soriano, M.P.C., Silva, M.F.G.F., Vieira, P.C., Fernandes, J.B., Rodrigues Filho, E., Magalhães, E.G., Magalhães, A.F., Pimenta, E.F., Souza, D.H.F., Glaucius, O., 2003. Enzymatic inhibition studies of selected flavonoids and chemosystematic significance of polymethoxylated flavonoids and quinolone alkaloids in Neoraputia (Rutaceae). J. Braz. Chem. 14, 380-387.

Mota, K.S.L., Dias, G.E.N., Pinto, M.E.F., Luiz-Ferreira, A., Souza-Brito, A.R.M., HirumaLima, C.A., Barbosa-Filho, J.M., Batista, L.M., 2009. Flavonoids with gastroprotective activity. Molecules 14, 979-1012.

Ngadjui, B.T., Dongo, E., Happi, E.N., Bezabih, M., Abegaz, B.M., 1998. Prenylated flavones and phenylpropanoid derivatives from roots of Dorstenia psilurus. Phytochemistry 48, 733-737.

Nitsch, J.P., Nitsch, C., 1956. Studies on the growth of coleoptile and first internode sections. A new sensitive, straight-growth test for auxins. Plant. Physiol. 31 94-111.

Oliveira, F.M., Santana, A.E.G., Conserva, L.M., Maia, J.G.S., Guilhon, G.M.P., 1996 Alkaloids and coumarins from Esenbeckia species. Phytochemistry 41, 647-649.

Passador, E.A.P., Silva, M.F.G.F., Rodrigues Filho, E., Fernandes, J.B., Vieira, P.C., Pirani, J.R., 1997. A pyrano chalcone and a flavanone from Neoraputia magnífica. Phytochemistry 45, 1533-1537.

Paulini, H., Waibel, R., Schimmer, O., 1989. Mutagenicity and structure-mutagenicity relationships of furoquinolines, naturally occurring alkaloids of the Rutaceae. Mut. Res. 277, 179-182.

Pavela, R., Vrchotová, N., 2013. Insecticidal effect of furanocoumarins from fruits of Angelica archangelic L. against larvae Spodoptera littoralis Boisd. Ind. Crop Prod. 43, 33-39.

Pick, A., Muller, H., Mayer, R., Haenisch, B., Pajeva, I.K., Weight, M., Bönisch, H., Müller, C.E., Wiese, M., 2011. Structure-activity relationships of flavonoids as inhibitors of breast cancer resistance protein (BCRP). Bioorg. Med. Chem. 19, 2090-2102.

Salas, M.P., Céliz, G., Geronazzo, H., Daz, M., Resnik, S.L., 2011. Antifungal activity of natural and enzymatically-modified flavonoids isolated from citrus species. Food Chem. 124, 1411-1415.

Sampaio, O.M., Silva, M.F.G.F., Veiga, T.A.M., King-Díaz, B., Lotina-Hennsen, B., 2012. Avaliação de furanocumarinas como inibidores da fotossíntese através de ensaios de fluorescência da Clorofila a. Quím. Nova 11, 2115-2118.

Santos, D.A.P., 2005. Busca de metabólitos bioativos em plantas das famílias Bignoniaceae e Rutaceae contra parasitas causadores de doenças tropicais. PhD Thesis, Universidade Federal de São Carlos, Maio.

Santos, D.A.P., Vieira, P.C., Silva, M.F.G.F., Fernandes, J.B., Rattray, L., Croft, S.I., 2009. Antiparasitic activities of acridone alkaloids from Swinglea glutinosa (BI.). Merr. J. Braz. Chem. Soc. 20, 644-651.

Sardari, S., Mori, Y., Horita, K., Micetich, R.G., Nishibe, S., Daneshtalab, M., 1999. Synthesis and antifungal activity of coumarins and angular furanocoumarins. Bioorg. Med. Chem. 7, 1933-1940.

Silva, L.F.R., Montoia, A., Amorim, R.C.N., Melo, M.R., Henrique, M.C., Numomura, S.M., Costa, M.R.F., Andrade Neto, V.F., Costa, D.S., Dantas, G., Lavrado, J., Moreira, R., Paulo, A., Pinto, A.C., Tadei, W.P., Zacardi, R.S., Eberlin, M.N., Pohlit, A.M., 2012. Comparative in vitro and in vivo antimalarial activity of the indole alkaloids ellipticine, olivacine, cryptolepine and a synthetic cryptolepine analog. Phytomedicine 20, 71-76.

Souto, A.L., Tavares, J.F., Silva, M.S., Diniz, M.F.F.M., Athayde-Filho, P.F., BarbosaFilho, J.M., 2011. Anti-inflammatory activity of alkaloids: An update from 2000 to 2010. Molecules 16, 8515-8534.

Souza, S.M., Delle-Monache, F., Smânia Jr., A., 2005. Antibacterial activity of coumarins. Z. Naturforsch. 60, 693-700

Tan, Q., Luo, X., 2011. Meliaceous limonoids: chemistry and biological activities. Chem. Rev. 111, 7437-7522.

Tomazela, D.M., Pupo, M.T., Passador, E.A.P., Silva, M.F.G.F., Vieira, P.C., Fernandes, J.B., Rodrigues Filho, E., Oliva, G., Pirani, J.R., 2000. Pyrano chalcones and a flavone from Neoraputia magnifica and their Trypanosoma cruzi glycosomal glyceraldehyde-3-phosphate dehydrogenase-inhibitory activities. Phytochemistry $55,643-651$.

Treutter, D., 2006. Significance of flavonoids in plant resistance: a review. Environ. Chem. Lett. 4, 147-157.

Velozo, E.S., Oliveira, D.J., Arruda, A.C., Vieira, P.C., Fernandes, J.B., Silva, M.F.G.F., Caracelli, I., Zukerman-Schpector, J., 1997. Rauianin, a new coumarin from Rauia resinosa. Nat. Prod. Res. 9, 237-244.

Wolfe, K.L., Liu, R.H., 2008. Structure-activity relationships of flavonoids in the cellular antioxidant activity assay. J. Agric. Food Chem. 56, 8404-8411.

Zhai, H., Zhao, C., Zhang, N., Jin, M., Tang, S., Qin, N., Kong, D., Duan, H., 2012. Alkaloids from Pachysandra terminalis inhibit breast cancer invasion and have potential for development as antimetastasis therapeutic agents. J. Nat. Prod. 75, 1305-1311. 